\title{
Linfoma esplénico de la zona marginal sin linfocitos vellosos en periferia
}

\author{
R. PILA PÉREZ, R. PILA PELÁEZ, P. ROSALES TORRES', V. A. HOLGUÍN PRIETO, \\ L. F. ALZATE GIRALDO \\ Servicios de Medicina Interna y ${ }^{I}$ Anatomía Patológica. Hospital Universitario "Manuel \\ Ascunce Domenech". Camagüey. Cuba
}

\author{
SPLENIC LYMPHOMA OF THE MARGINAL ZONE WITHOUT \\ PERIPHERAL HAIRY LYMPHOCYTES
}

\begin{abstract}
RESUMEN
Se presenta el caso de un paciente de 34 años de edad con el diagnóstico de linfoma esplénico de la zona marginal, una entidad poco reconocida en nuestro medio. Se describen algunas de sus características y se resalta el diagnóstico, el cual debe ser precoz para el tratamiento óptimo de esta patología. Esta entidad puede debutar como una esplenomegalia gigante requiriendo tener presente todas las causas que son capaces de producirla.
\end{abstract}

PALABRAS CLAVE: Linfoma extranodal. Linfoma esplénico de la zona marginal. Esplenomegalia gigante.

\begin{abstract}
This paper reports on a case of a 34-year male patient diagnosed for splenic lymphoma of the marginal zone, a rare entity in our milieu. Features of the disease are described. Early diagnosis is a must for optimum treatment of such a pathology, whose onset can be giant splenomegalia. All possible causes are to be considered.
\end{abstract}

KEY WORDS: Extranodal lymphoma. Marginal zone splenic lymphoma. Giant splenomegalia.

Pila Pérez R, Pila Peláez, R, Rosales Torres P, Holguín Prieto VA, Alzate Giraldo LF. Linfoma esplénico de la zona marginal sin linfocitos vellosos en periferia. An Med Interna (Madrid) 2007; 24: 396-398.

\section{INTRODUCCIÓN}

El linfoma esplénico de la zona marginal (LEZM) es un desorden linfoproliferativo primario del bazo que se ha descrito recientemente, en la mayoría de los casos afecta a pacientes de mayor edad (1) y son considerados como linfomas de células B extranodales indolentes (2).

Independientemente de su baja agresividad, su progresión histológica ha sido descrita en esporádicos estudios e igualmente su frecuencia junto con sus características generales. Las anomalías moleculares de éste fenómeno son conocidas en el momento actual aunque continúan ampliándose los conocimientos sobre este proceso (3).

El linfoma primario de bazo es una forma de presentación muy rara de los linfomas, pues se calcula su incidencia en $1 \%$ de los mismos (4).

En la presente comunicación aportamos un caso de LEZM a cuyo diagnóstico se llegó por aspiración de la médula ósea conjuntamente con la esplenectomía y el estudio histopatológico del bazo, siendo este el primer caso reportado en nuestro hospital desde hace 45 años.

\section{CASO APORTADO}

Paciente de 34 años, varón, blanco, al cual se le diagnosticó hace 4 años un linfoma no Hodgkin ( $\mathrm{LNH}$ ) de células grandes y pequeñas por estudio histopatológico de un ganglio, recibiendo por dicha razón varios esquemas de tratamiento que él desconoce. Hace dos años aproximadamente comenzó con pérdida de peso, sensación de opresión en el abdomen y fiebre de $38^{\circ} \mathrm{C}$, acudiendo a un facultativo quien le indicó diferentes medicamentos, con relativa mejoría de sus síntomas, hasta hace alrededor de 30 días en que presentó dolor en el costado izquierdo, con sensación de un "salto" en esa zona, diaforesis, fiebre de $37.5-39^{\circ} \mathrm{C}$, así como astenia, anorexia y pérdida de peso de $20 \mathrm{~kg}$, por lo que es hospitalizado.

En la exploración física destaca nutrición deficiente, palidez marcada de piel y mucosas, fiebre de $38{ }^{\circ} \mathrm{C}$.

Disminución del murmullo vesicular en base pulmonar izquierda, latidos cardíacos taquicárdicos, soplo sistólico mitral II/VI (Levine), TA: 100/60 mm Hg; frecuencia cardíaca central de $100 \mathrm{lat} / \mathrm{min}$. En el abdomen se palpa hepatomegalia que rebasa en un centímetro el reborde costal, con esplenomegalia que llega a la fosa ilíaca derecha, no dolorosa, de consistencia dura, contornos regulares y que contacta con el lóbulo izquierdo del hígado. No se palpan adenopatías en las cadenas ganglionares periféricas. El res-

Trabajo aceptado: 29 de marzo de 2007 
to de los exámenes de otros aparatos y sistemas fueron normales. Exploración rectal y fondo de ojo: normales.

Estudios analíticos: hemoglobina: $2 \mathrm{~g} / \mathrm{dl}$, hematócrito: 0,12, leucocitos: $11,3 \times 10^{9} / 1$ con fórmula diferencial de: linfocitos: 0.83 , neutrófilos 0,17 , linfocitosis de $9,379 \times 10^{9} / 1$, velocidad de sedimentación globular: $142 \mathrm{~mm} / 1^{\mathrm{a}} \mathrm{h}$, conteo de reticulocitos: 3 x $10^{3} / \mathrm{l}$, plaquetas: 60 x 10\%/1, VCM: $71 \mathrm{fL}$. Tiempos de coagulación y sangrado, protrombina, TPT (Kaolín), glucemia, creatinina, iones, enzimas hepáticas: normales, excepto la LDH: $640 \mathrm{U} / \mathrm{l}$. HBsAg y anticuerpos para virus $\mathrm{C}$, gota gruesa, prueba de Mantoux 5-PPD: negativos. VDRL y VIH: negativos.

Radiografía de tórax: reveló discreto derrame pleural izquierdo que remitió en ulteriores controles. ECG: taquicardia sinusal. Ultrasonografía abdominal: tumoración en hipocondrio izquierdo que se extiende hasta la fosa ilíaca derecha de aproximadamente $33 \times 20 \times 12 \mathrm{~cm}$ y que por su forma corresponde a una esplenomegalia gigante, los contornos del órgano son regulares existiendo desplazamiento renal y del lóbulo izquierdo hepático. La estructura de la cara anterior esplénica se aprecia normal. En el interior del órgano existe una infiltración heterogénea de aspecto maligno.

Tomografía axial computarizada (TAC) de retroperitoneo: $\sin$ alteraciones. El examen gammagráfico constató una hepatomegalia discreta inespecífica y un bazo gigante no captante. El aspirado de la médula ósea practicado en dos oportunidades fue sospechoso de mielofibrosis, pero sin diagnóstico de certeza. Biopsia de médula ósea: muestra escasa, existe presencia de patrones micronodulares, intersticial y paratrabecular, con células medianas y pequeñas, siendo el diagnóstico el de una médula infiltrada por un LNH de bajo grado. Después de la administración de cuatro paquetes de sangre total y mejorar su estado general fue intervenido quirúrgicamente con los siguientes hallazgos operatorios: esplenomegalia de $3900 \mathrm{~g}$ con mensuraciones de 33 × 21 x $12 \mathrm{~cm}$. $\mathrm{Al}$ corte se observa presencia de un infiltrado nodular pequeño, de color gris-blanquecino que afecta a toda la parte interna del órgano fundamentalmente la pulpa gris, dándole al órgano una consistencia dura-carnosa (Fig. 1). Se encuentran dos adenopatías de $2 \times 2,5$ $\mathrm{cm}$ a nivel del hilio esplénico. Biopsia de cuña hepática: normal.

Conclusión: Linfoma no Hodgkin de células B de bajo grado, extranodal primario de bazo, tipo linfoma de zona marginal sin linfocitos vellosos en periferia (Fig. 2).

Después de la operación fue transfundido en dos oportunidades, comenzando antibioticoterapia y cuidados generales, siendo dado de alta con estudios de laboratorio, hematológicos e imagenológicos normales. No se aplica quimioterapia por estar en remisión después de la esplenectomía y no demostrar enfermedad activa hasta el momento.

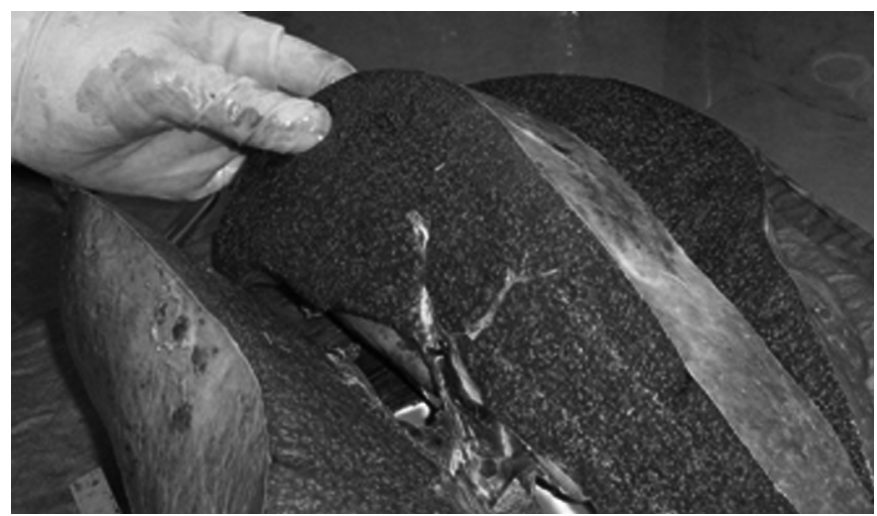

Fig. 1. Esplenomegalia gigante de consistencia dura con cápsula conservada. Obsérvese en la superficie de corte como el infiltrado tumoral forma pequeños nódulos blanquecinos perlados típicos.

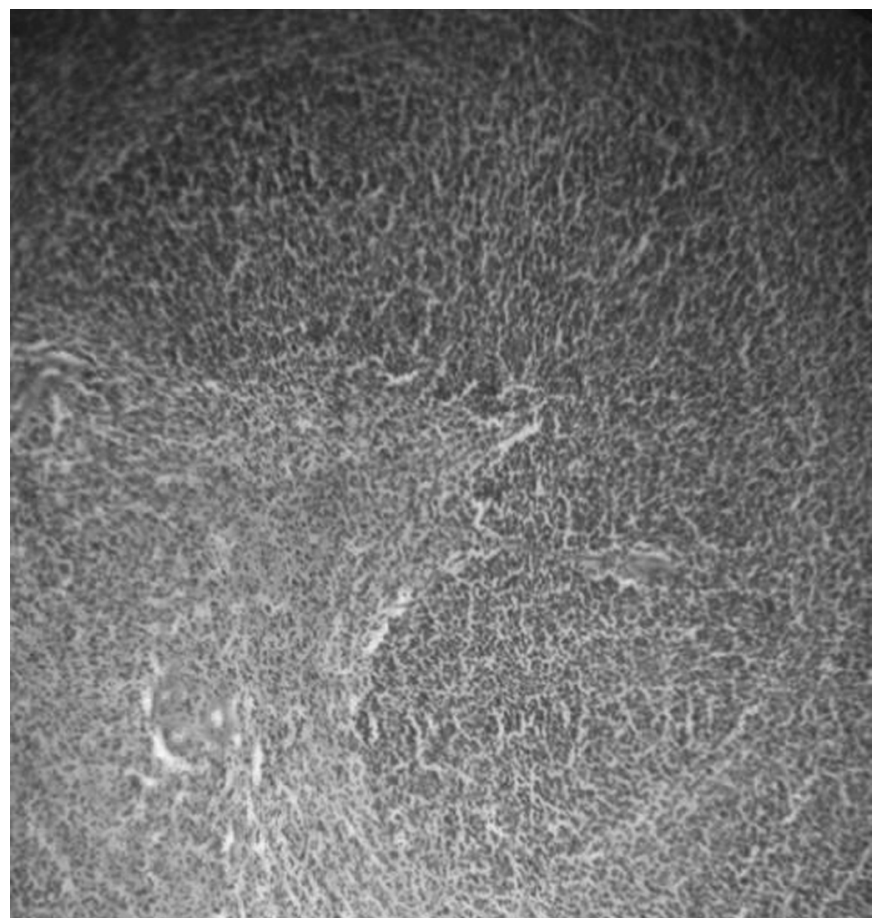

Fig. 2. Microfotografía donde se muestra un folículo esplénico (zona oscura) que está siendo obliterado y reemplazado por las células neoplásicas (zonas claras) (H/E-20x).

\section{DISCUSIÓN}

Cen y cols. (5) en un estudio realizado en China entre 1976 y el 2002 encontraron 458 pacientes con el diagnóstico de linfoma, de los cuales 139 tenían localización extranodal para un 30,3\% y de éstos, sólo $15(10,8 \%)$ tenían localización esplénica. López y cols. (6) en su investigación en España, de 382 pacientes con LNH de células B encontraron localización extranodal en 118 (31\%) y muy escasos con localización en el bazo; mientras que Krol y cols. (7) en Holanda en su serie de 389 pacientes encontraron un $20 \%$ con localización extranodal y reportan igualmente poca cantidad de casos con localización esplénica. Erlemann y cols. (8) señalan que alrededor del $30 \%$ de los LNH son extranodales y ocurren en el abdomen, en el bazo y en el hígado.

El LEZM y el linfoma esplénico nodal de la zona marginal (LENZM) son entidades recientemente descritas y separadas como dos entidades clínicas patológicas diferentes (9). Ambos son dos tipos raros de linfoma, con muy bajo índice de sospecha en su diagnóstico, no obstante, con el conjunto de alteraciones moleculares y estudios clínicos puede aclararse el diagnóstico de estos procesos no muy bien caracterizados dentro de las enfermedades neoplásicas hematológicas. Los LEZM son enfermedades que afectan al bazo, la médula ósea y la sangre periférica como primera manifestación de la enfermedad, como fue observado en nuestro enfermo.

El diagnóstico se realiza basado en los estudios histopatológicos y auxiliado por el cuadro clínico (3), tal y como se observó en este caso.

El LEZM es un linfoma indolente en el que pocos casos pueden continuar un curso agresivo $(1,9)$. El estudio molecu- 
lar en esta entidad está comenzando a revelar nuevos diagnósticos y marcadores que sirven de pronóstico al mismo tiempo que se pueden aplicar nuevos agentes terapéuticos $(3,7)$. Por otro lado, el LENZM es una neoplasia de células B originadas en el nódulo linfático y cuya histología recuerda la infiltración nodal por MALT o un LEZM (9).

Los linfomas primarios del bazo en pacientes con esplenomegalia considerados como idiopáticos son significativos como lo muestra la investigación de Carr y cols. (10), quienes entre 1994 y 2001, recibieron 86 casos con esplenomegalia, de los cuales 18 eran considerados como idiopáticos por los diferentes estudios para esta enfermedad; de éstos, 7 (39\%) fueron diagnosticados de linfoma y 5 eran LEZM, este estudio no sólo sirvió para el diagnóstico (de ellos tres requirieron quimioterapia, y cuatro estaban en remisión por sus esplenectomías y no tenían evidencia de enfermedad activa como ocurrió en nuestro caso) sino también para valorar las características anatómicas del bazo: en este estudio los bazos medían como promedio $21 \mathrm{~cm}$ con un rango de $14-34 \mathrm{~cm}$ y un peso promedio de $996 \mathrm{~g}$ con un rango de 320-1840 g, en nuestro enfermo el bazo medía $33 \mathrm{~cm}$ y pesaba $3900 \mathrm{~g}$, lo que lo caracterizaba como una esplenomegalia gigante.

Zhang y cols. (11) en un análisis de 23 casos de linfoma primario del bazo sometidos a esplenectomía, uno de ellos sólo para exploración y el resto, 22 (96\%), para tratamiento, encontraron que todos los casos después del estudio histopatológico tenían diagnóstico correcto y recibieron tratamiento adyuvante con quimioterápicos y fueron estratificados para conocer la supervivencia a los cinco años las cuales fueron de 50, 40 y $10 \%$, respectivamente, según que el estadio fuera I, II o III. Además de los exámenes de ultrasonido y TAC, los cuales tienen un valor importante en el diagnóstico de este tipo de proceso ocupantes de espacio y que junto a su inocuidad y bajo costo, hacen de los mismos un procedimiento diagnóstico de primer orden (8), como fue observado en nuestra enferma.

La esplenectomía, en ocasiones junto con la quimioterapia, pueden ofrecer una terapéutica óptima a los pacientes con linfomas esplénicos y tener por tanto un valor diagnóstico de suma importancia (10), todo ello apreciado en este paciente. La esplenectomía se practica tanto en la enfermedad de Hodgkin como en el LNH, por hiperesplenismo resultante de la enfermedad de base y con menor frecuencia para el control de los síntomas asociados con esplenomegalia masiva; además en los casos de esplenomegalia no diagnosticada, este procedimiento permite realizar el diagnóstico histológico, los cuales si permanecen sin diagnóstico, mas tarde desarrollarán un linfoma (12).

La esplenectomía tiene baja mortalidad y morbilidad, generalmente ofrece la corrección de la citopenia hematopoyética y el diagnóstico correcto, lo cual permite la administración de la quimioterapia, adecuada o no de acuerdo al estado del paciente y la remisión de la enfermedad, de no demostrar actividad de la enfermedad (10-12); como ocurrió en este caso, en el cual no hemos impuesto quimioterapia y se encuentra en buen estado clínico, con exámenes de laboratorio e imagenológicos sin alteraciones hasta el momento actual.

\section{Bibliografía}

1. Wang S, Olson N, Zukemberg L, Harris N. Splenic marginal zone lymphoma with micronodular T-cell rich B-cell lymphoma. Am J Surg Pathol 2006; 30: 128-32.

2. Camacho F, Mollejo M, Algara P, Wavas C, Hernández J, et al. Progression to large B-cell lymphoma in splenic marginal zone lymphoma: A description of a series of 12 cases. Am J Surg Pathol 2001; 25: 1268-76.

3. Liu W, Yang Z, Zeng L, Zhang W, Li F. The relationship of clinicopathology and inmunophenotypes in non-Hodgkin's lymphomas of the spleen. Zhong Hua Bin Li Xue Za Zhi 2001; 30: 93-6.

4. Ambulkar I, Kulkarni B, Borges A, Jaganmath P, Advani S. Primary non-Hodgkin's lymphoma of the spleen presenting as space occupyieng lesion: a case report and review of literature. Leuk Lymphoma 2006; 47: $135-9$

5. Cen X, Guo H, Wu S, Wang Y, Qiu Z, Wang W, et al. Primary extranodal lymphomas: analyses of clinical characteristics and misdiagnosis of 139 cases. Beijing Da Xue Xue Bao 2003; 35: 143-5.

6. López A, Colomo L, Jiménez M, Bosh F, Villamor N, Arenillas L, et al. Difusse large B-cell lymphoma: Clinical and biological characterization and outcome according to the nodal or extranodal primary origin. J Clin Oncol 2005; 23: 2797-804.

7. Krol A, Le cassie S, Snijder S, Kluin-Nelemaws J, Kluin P, Noordijk E. Primary extranodal non-Hodgkin's lymphoma (NHL): the impact of alternative definitions tested in the comprehensive cancer centre west population-based NHL registry. Ann Oncol 2003; 14: 131-9.

8. Erlemann R, Schmitz A, Stroeken M, Vbring Vom Barany R, Ger Harz J. Extranodal lymphomas infradiafragmal. Radiologe 2002; 42: 971-87.

9. Mollejo M, Camacho F, Algara P, Ruiz-Ballesteros E, García F, Piris $\mathrm{M}$, et al., and splenic marginal zone B-cell lymphomas. Hematol Oncol 2005; 23: 108-18.

10. Carn J, Shura Fa M, Velanovich V. Surgical indications in idiopathic splenomegaly. Arch Surg 2002; 137: 64-8.

11. Zhang R, Wang D, Li Q, Sun T, Hao X. Primary lymphoma of the spleen: clinical analysis of 23 cases. Zhonghua Wai Ke Za Zhi 2002; 40: 208-9.

12. Hammer R, Glick A, Greer J, Collins R, Cousar J. Splenic marginal zone lymphoma. A distinct B cell neoplasm. Am J Surg Pathol 1996; 20: 613-26. 